\title{
The Fabrication of Automobile Components by Applying Electromagnetic Stirring in Semisolid Process
}

\author{
H. H. Kim ${ }^{1}$ and C. G. Kang ${ }^{2}$ \\ ${ }^{1}$ Precision Manufacturing Systems Division, Pusan National University, Pusan 609-735, Republic of Korea \\ ${ }^{2}$ School of Mechanical Engineering, Pusan National University, Pusan 609-735, Republic of Korea
}

Correspondence should be addressed to C. G. Kang, cgkang@pusan.ac.kr

Received 1 September 2010; Accepted 19 November 2010

Academic Editor: Shoujin Sun

Copyright (c) 2011 H. H. Kim and C. G. Kang. This is an open access article distributed under the Creative Commons Attribution License, which permits unrestricted use, distribution, and reproduction in any medium, provided the original work is properly cited.

\begin{abstract}
This paper describes a rheo-forming process for the development of automobile components, such as knuckle, by using rheology material with electromagnetic stirring (EMS) system equipment. The effects of several process and metallurgy parameters such as stirring current, stirring time, pouring temperature, forming pressure, tip velocity, fraction of primary phase, and its morphology and distribution, on the final products are reviewed and discussed. A variety of simulation studies are conducted. In addition, the effect of the vacuum-assisted method on the performance of rheo-forged products is introduced. The EMS is an effective process to improve a feed stock in the rheo-forming process with improved mechanical properties.
\end{abstract}

\section{Introduction}

Recently, the car industry has required lightweight parts to improve gas mileage and mitigate the impact of damaging emissions on the environment, which are thought to contribute to depleting the ozone layer, increasing greenhouse gases, and producing acid rain $[1,2]$. Forming processes such as casting and forging, hot forging, and low-pressure casting have allowed lightweight aluminum alloy-based component to be used in passenger cars, but they have not been adapted to mass-production due to a lack of product reliability, increased costs, and excessive initial investment.

The die casting process, that is, the forming process that fills mold cavities with molten metal, has advantages for the mass production of thin parts with complex shapes which have little need for mechanical strength. However, the process is inappropriate for producing parts with high strength requirements because defects such as turbulent flow-induced air entrapment could result as the melt flows into the mold cavities [3]. Moreover, the forging process has several limitations in producing precise parts and productivity because the forming process has multiple steps. Conversely, the mechanical properties of the parts appear to be uniform and stable [4].
Therefore, the electromagnetic stirring forming process, which is capable of producing light automobile parts with high strength, has been required to promote low mechanical properties of parts $[5,6]$. Electromagnetic stirring (EMS) is a process that modifies the microstructure of alloy before or during the forming process. These microstructures are created during solidification to spherical primary $\alpha$-Al phase particles and distributed into the eutectic phase by strongly stirring the molten metal at the initial stage of solidification.

This paper describes a rheo-forming process for the development of automobile components by using rheology material with EMS system equipment such as knuckle, arm and special designed bracket module. In addition, the effect of the vacuum-assisted method on the performance of rheoforged products was introduced.

\section{Fabrication of Arm Component Medium-Pressure Type with EMS}

2.1. Apparatus for Electromagnetic Stirring. This study obtains the experimental data applicable to the forming process of the resulting products to be produced by electromagnetic stirring in terms of investigation of the relation 


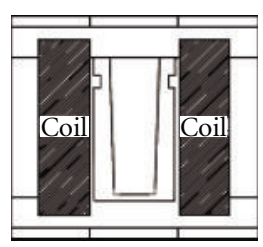

(a)

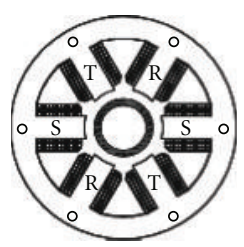

(b)

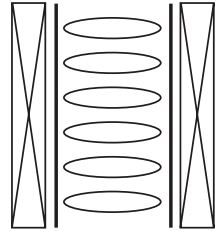

(c)
Figure 1: The schematic diagram of the apparatus with electromagnetic stirrer: (a) Front view of EMS, (b) top view, (c) stirring direction.

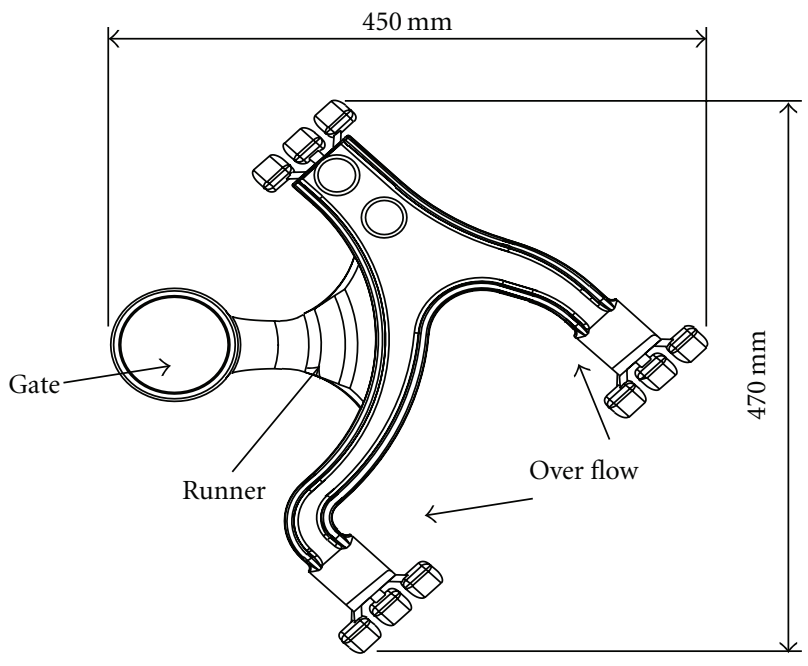

FIGURE 2: Geometry of runner system and arm part.

between the properties of A356 alloys. This includes primary $\alpha$-Al phase particle sizes, their distribution state, spherical structures and electromagnetic stirring current and time. An electromagnetic stirrer is classified with a vertical and horizontal stirrer. In this study, a horizontal electromagnetic stirrer was employed to get experimental data, and the schematic electromagnetic stirrer used in this experiment was illustrated in Figure 1(a). The horizontal electromagnetic stirrer used in this study was manufactured so as to contain three phases and three poles, with each phase located circumferentially so that the current flows through the coils, as shown in Figure 1(b). The electromagnetic force appears to arise toward the circumferential direction, as shown in Figure 1(c). To manufacture the electromagnetic stirrer used in this work, the design and manufacture of the core to fix the coil were completed first. The core holds the coil that is wound to the core, which is in turn fabricated to laminate the 0.35-mm-thick steel plate.

2.2. Mold Design and Simulation. This study adopted the Ostwald-de Waele rheology model. Taking into consideration these characteristics of electromagnetic stirring, mold design of arm parts was prepared using MAGMAsoft (casting analysis code) and was optimized with prediction of casting defects through filling analysis and solidification. Then, the design plan was applied to manufacturing the mold used in this study.

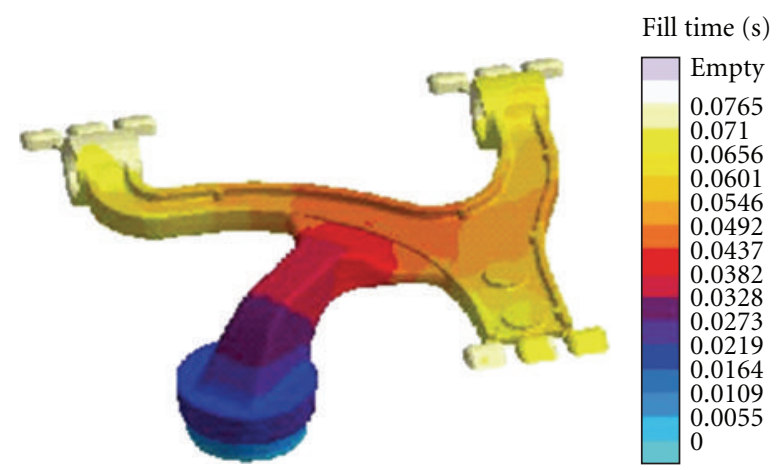

Figure 3: Filling time distribution of arm part.

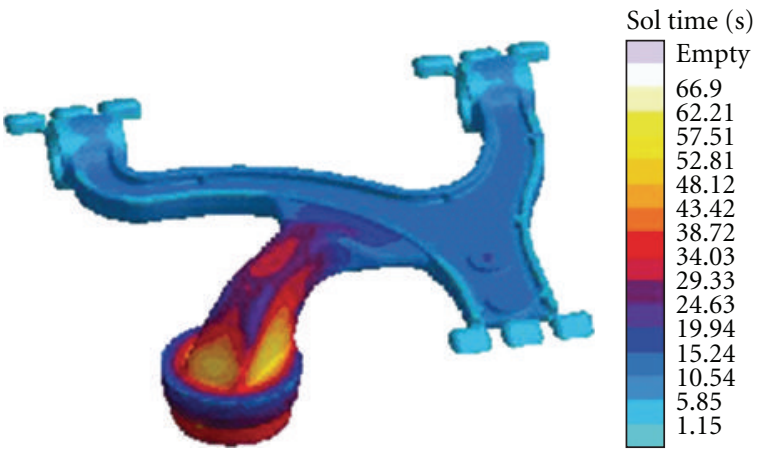

FIgURE 4: Solidification time distribution of arm part.

Figure 2 depicts a runner system including the geometry of a gate and an overflow. Figure 3 shows distribution of filling time of arm products into mold cavity. The filling time, the passing time through the gate, and the time for filling the mold cavity of products are $0.074,0.0437$, and $0.0327 \mathrm{~s}$, respectively. Figure 3 shows the filling time distribution of arm parts. Change in melt flows in the cavity as a function of filling time found that good filling behavior is achieved with completion of overflow. In addition, temperature deviation of melts in the cavity resulted within $3^{\circ} \mathrm{C}$ due to the short period of filling. In addition, the final filling is completed with the minimum temperature of melt in the cavity of $609^{\circ} \mathrm{C}$ and solid fraction of $75 \%$. Figure 4 shows the distribution of solidification time of arm products. The final solidification was completed in $66.9 \mathrm{~s}$, and solidification of product parts was also completed in $16.37 \mathrm{~s}$ after the final filling. Also, directional solidification from product parts to gate parts took place. Utilizing these results, the forming condition of practical products like pressing time after filling was obtained. Figure 5(a) shows the distribution of hotspots in the arm products. Hotspots were mostly distributed at the gate and the overflow due to directional solidification toward the gate. As illustrated in Figure 5(b), a heating line was facilitated surrounding the arm products for the prevention of the lowering of the temperature and control of solidification and stabilization in the temperature of the mold since shrink pores may take place at locations having formation of hotspots. 


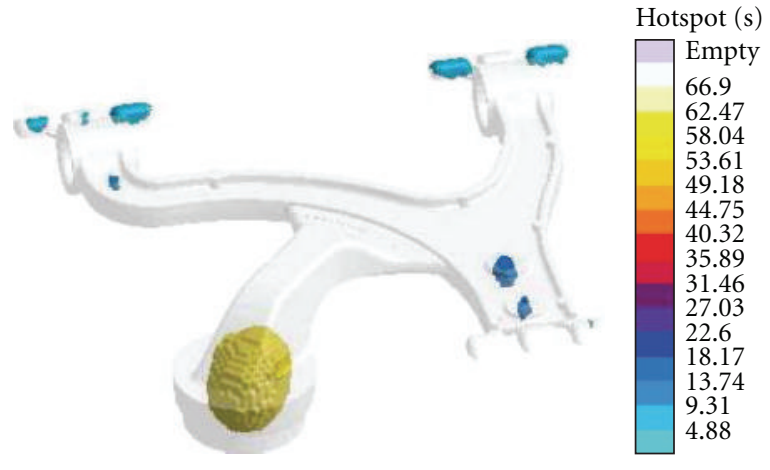

(a) Hotspot distribution of arm

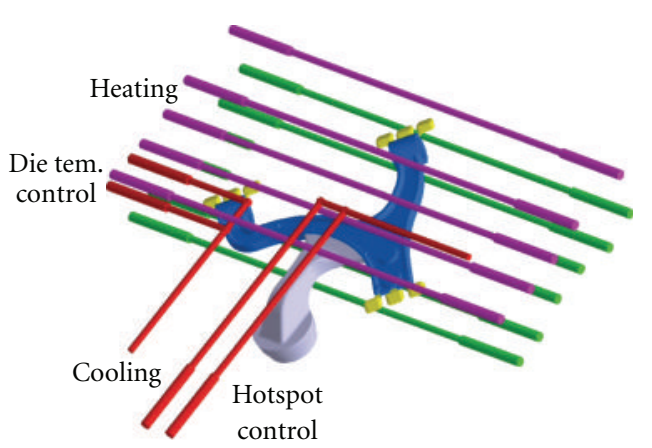

(b) Heating line

FIgURE 5: Hotspot distribution of arm part and heating line.

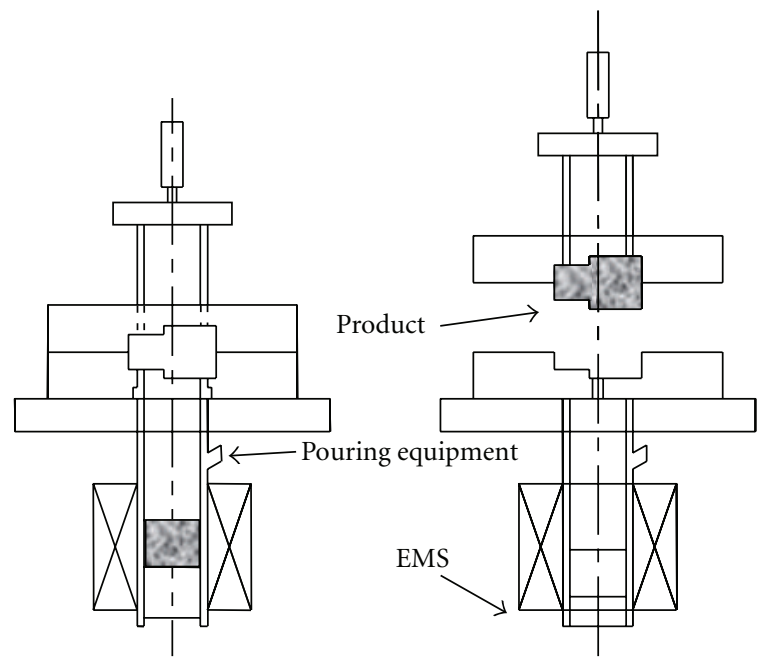

(a)

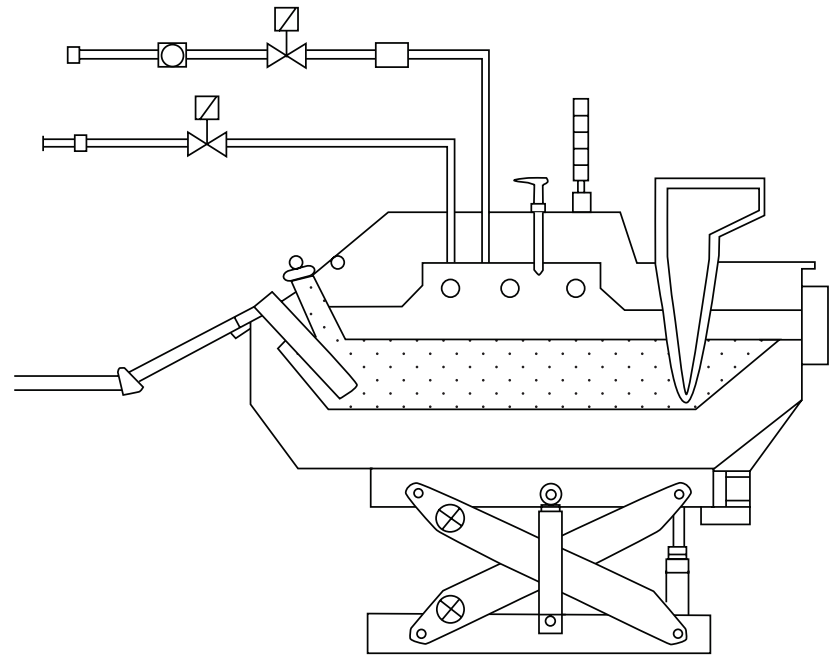

(b)

FIGURE 6: Schematic diagram for casting with EMS: (a) medium vertical die casting press; (b) continuous pouring of molten alloy (Al dosing furnace).

2.3. Results of Arm Fabrication by Rheo-Casting. Manufacturing sleeves is important in the forming process utilizing electromagnetic stirrers. Nonmagnetic material 19\%Cr$9 \% \mathrm{Ni}$ STS 304 is currently used as a sleeve. STS 304 was selected as a sleeve material since the characteristics of STS 304 provides nonmagnetic properties at room temperature and good machinability. The inner and outer diameters of the sleeve are 80 and $130 \mathrm{~mm}$, respectively. Figure 6 illustrates a schematic diagram for casting with EMS.

Figure 7 shows photographs of arm products formed by EMS in terms of each forming condition. In the case of pressure of 300 bar $(300 \mathrm{bar} \times 14.5 \mathrm{psi} \times 0.001 \times 5.895 \mathrm{MPa}$ $=26 \mathrm{MPa}$ ) and a speed of $0.2 \mathrm{~m} / \mathrm{s}$, insufficient forming of products due to solidification of melt during filling into the cavity took place and surface quality was not acceptable due to a lack of transfer of filling pressure to the cavity. With injection speed at a range of $0.2-0.3 \mathrm{~m} / \mathrm{s}$, sufficient products were obtained and good surface quality was achieved. In the case of an increase of injection speed up to $0.3-0.5 \mathrm{~m} / \mathrm{s}$, the melt spread into the parting line of the mold due to high-speed filling and surface quality of products was not achieved. Surface quality of products was found to be better with an increase of injection pressure with an increase of forming pressure to 450 bar to investigate the effect of forming pressure.

Figure 8(b) shows microstructures at each position according to each point as depicted in Figure 8(a). The samples of arm products were formed with EMS at $60 \mathrm{~A}$ for $10 \mathrm{~s}$ and were sized with $5 \mathrm{~mm}$ long and $5 \mathrm{~mm}$ wide. As a result of microstructural observation, it was found that the primary $\alpha$-Al phase particles were uniformly distributed through entire products and the distributed primary $\alpha-\mathrm{Al}$ phase particles reached fine and globularly.

\section{Fabrication of Tower Sprocket Component by EMS Rheo-Casting}

3.1. Procedure of Rheo-Forming. In this experiment, A356 aluminum alloy was used for making slurry with the same EMS system (Section 2.1). 


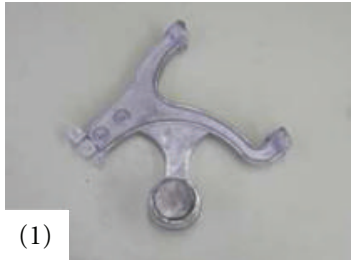

(a)

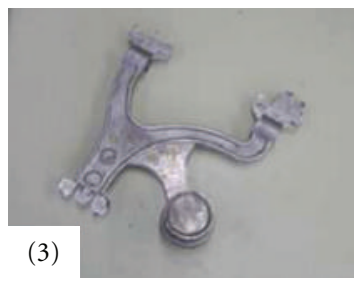

(c)

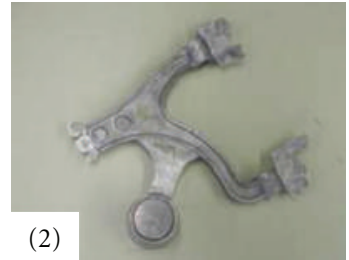

(b)

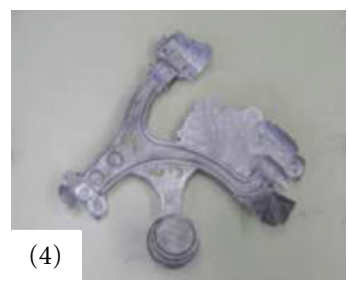

(d)
Figure 7: Photographs of arm part according to velocity and pressure (at 75\% solid fraction): (1) $0.2 \mathrm{~m} / \mathrm{s}$ and $300 \mathrm{bar}$; (2) $0.3 \mathrm{~m} / \mathrm{s}$ and 300 bar; (3) $0.3 \mathrm{~m} / \mathrm{s}$ and $450 \mathrm{bar}$; (4) $0.5 \mathrm{~m} / \mathrm{s}$ and 450 bar.

TABLE 1: The conditions of rheo-casting process.

\begin{tabular}{lccc}
\hline No. & $\begin{array}{c}\text { Casting pressure } \\
(\mathrm{MPa})\end{array}$ & $\begin{array}{c}\text { Low velocity }\left(V_{L}\right) \\
(\mathrm{m} / \mathrm{s})\end{array}$ & $\begin{array}{c}\text { High velocity } \\
\left(V_{H}\right)(\mathrm{m} / \mathrm{s})\end{array}$ \\
\hline 1 & 35 & 0.1 & 0.3 \\
2 & 35 & 0.1 & 0.5 \\
3 & 35 & 0.1 & 0.7 \\
4 & 35 & 0.1 & 1.0 \\
5 & 20 & 0.1 & 1.0 \\
6 & 35 & 0.1 & 1.0 \\
7 & 50 & 0.1 & 1.0 \\
8 & 60 & 0.1 & 1.0 \\
\hline
\end{tabular}

Figure 9 shows a location of rheological material and the tip in the sleeve at both low velocity and high velocity. After putting solid fraction-controlled (20\% and 50\%) rheological material into the cavity and combining shot sleeve and lower mold with concentration, the tip velocity maintains to be low so as to reduce entrapment of air bubbles while the rheological material arrives to gate entrance. The movement of tip is kept to be high velocity so that the segregation of the solid and liquid phase is prevented by quickly forwarding the tip as soon as the material passes the gate entrance. In this study, therefore, the experiment was evaluated with regard to low velocity of $V_{L}=0.1 \mathrm{~m} / \mathrm{sec}$ and high velocity of the tip movement ranging from $V_{H}=0.3 \mathrm{~m} / \mathrm{sec}$ to $1.0 \mathrm{~m} / \mathrm{sec}$, as shown in Table 1.

3.2. Results of Tower Sprocket Fabrication by Rheo-Casting. Figures 10 (a) to 10 (d) show the filling behaviors when the velocities of injection are low velocity of $V_{L}=0.1 \mathrm{~m} / \mathrm{sec}$ at solid fraction $f_{s}=0.5$ and high velocity of $V_{H}=0.3 \mathrm{~m} / \mathrm{sec}$ to $V_{H}=1.0 \mathrm{~m} / \mathrm{sec}$. No filling parts were observed at the high injection velocity of $0.3,0.5$, and $0.7 \mathrm{~m} / \mathrm{sec}$. The filling was only completed at $V_{L}=0.1 \mathrm{~m} / \mathrm{sec}$ and $V_{H}=1.0 \mathrm{~m} / \mathrm{sec}$, as

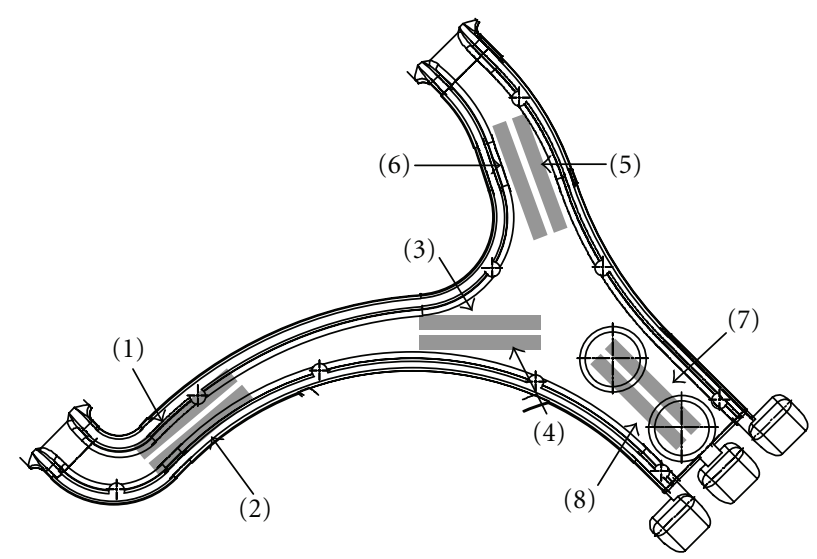

(a) Position to investigate the microstructure
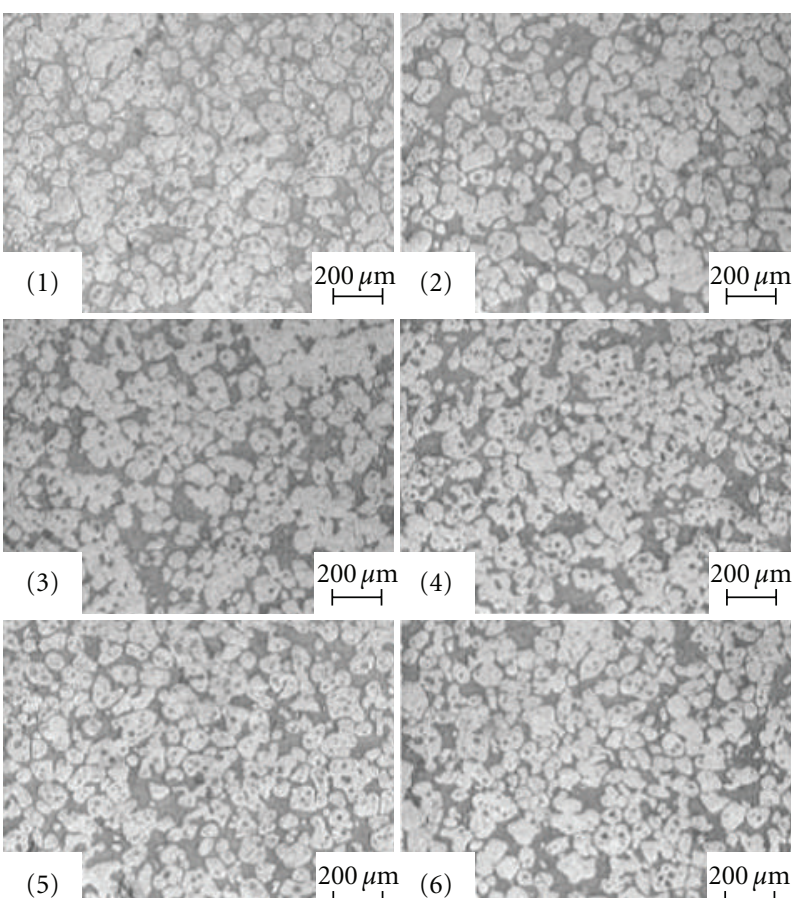

(5)
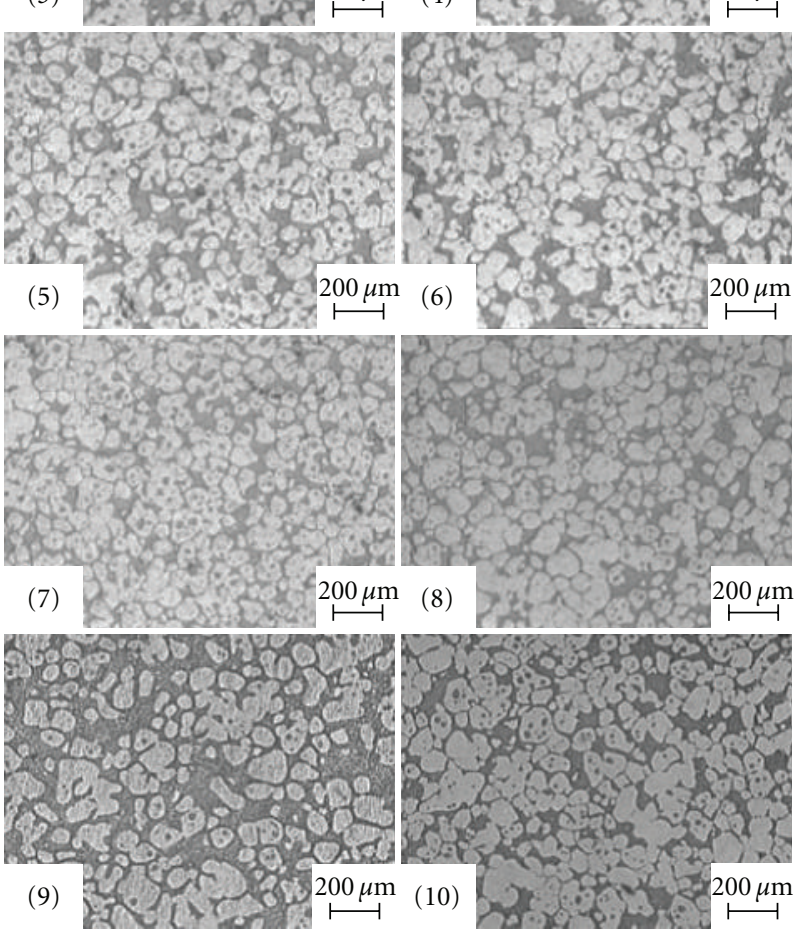

(b) microstructure at each position

FIGURE 8: Microstructures at each position according to each point $(C=60 \mathrm{~A}, \mathrm{ts}=10 \mathrm{~s}$ and solid fraction of $75 \%)$. 


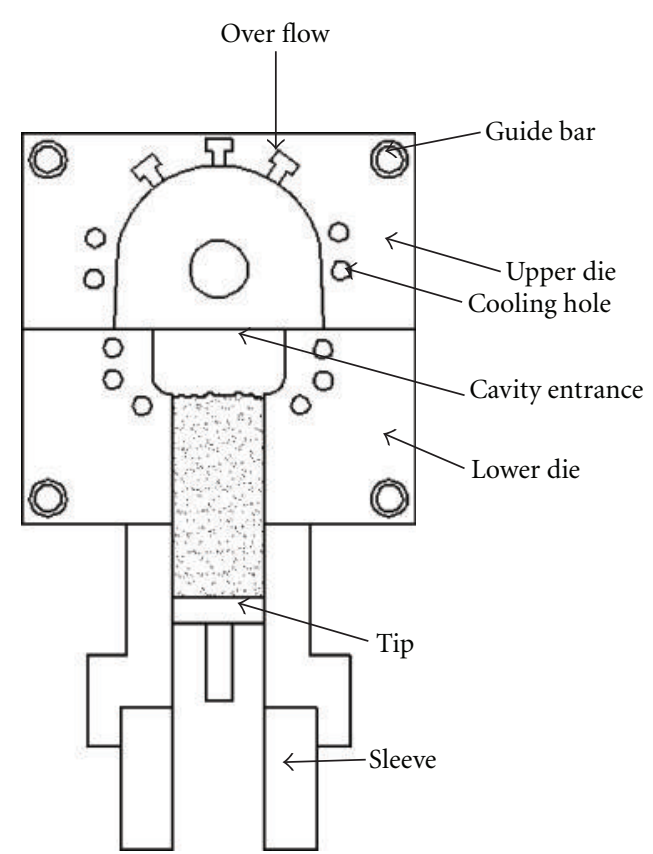

(a) Pouring and contact between lower die and shot sleeve
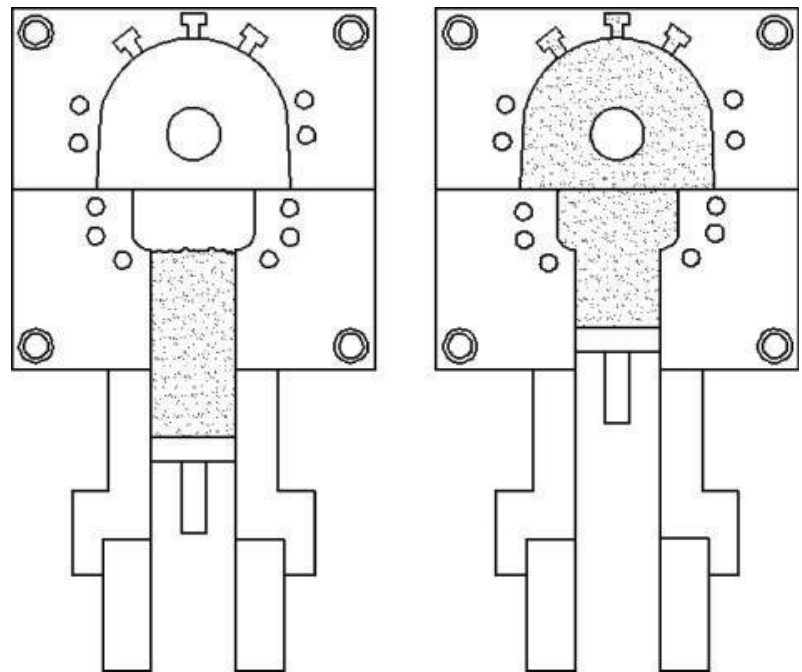

(b) Movement of the tip by low velocity until meniscus of the melt arrives at the die entrance

FIGURE 9: The plunger position for variation of velocity.

shown in Figure 10(d). Thus, the casting parameters for the case of Figure 10(d) were used to obtain the complete cast product. As shown in Table 1, after completing to fill the die cavity, pressure of injection was controlled by maximum pressure of $60 \mathrm{MPa}$ so that microstructure of the part is refined.

Figure 11 shows the external appearance of products formed under the condition, $V_{L}=0.1 \mathrm{~m} / \mathrm{sec}, f_{s}=0.2$, and $V_{H}=1.0 \mathrm{~m} / \mathrm{sec}$, which was optimized to obtain the sound product through the preliminary experiment carried out in this study. The thickness of side part of the product is $6 \mathrm{~mm}$ and the total weight of the net product is $1.61 \mathrm{~kg}$ without gate part which occupies $40 \%$ of the product.

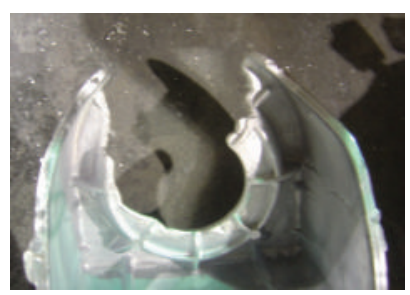

(a) $V_{H}=0.3 \mathrm{~m} / \mathrm{sec}$

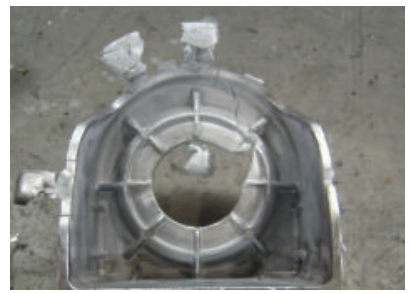

(c) $V_{H}=0.7 \mathrm{~m} / \mathrm{sec}$

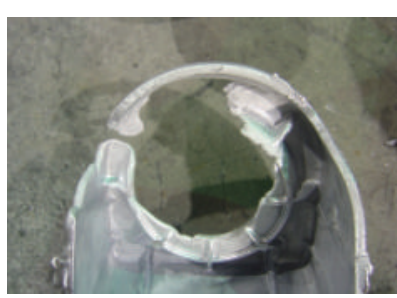

(b) $V_{H}=0.5 \mathrm{~m} / \mathrm{sec}$

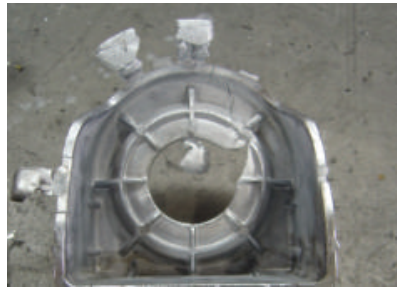

(d) $V_{H}=1.0 \mathrm{~m} / \mathrm{sec}$
Figure 10: Photograph of fabricated part according to injection velocity in high-speed zone $\left(V_{L}=0.1 \mathrm{~m} / \mathrm{sec}\right.$, Solid fraction: $\left.50 \%\right)$
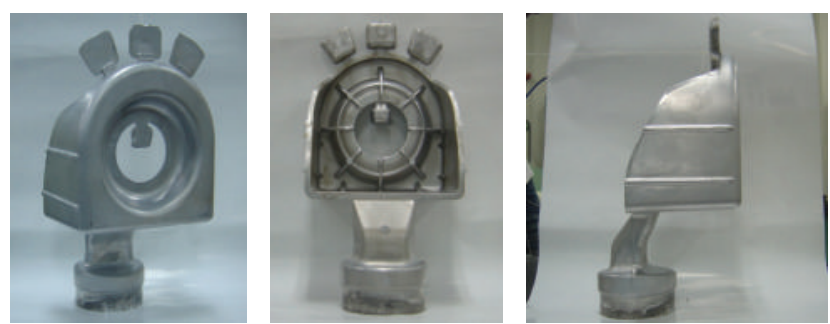

Figure 11: A photograph of products fabricated by vertical type squeeze machine $\left(V_{L}=0.1 \mathrm{~m} / \mathrm{sec} V_{H}=1.0 \mathrm{~m} / \mathrm{sec}\right.$, Solid fraction: $20 \%)$.

In this study, the shape of the cast product was selected to be channel shape structure which has complicate shape and rapidly changing direction of the melt flow. Through conventional rheology die casting process, it is considerably difficult to obtain the cast product which has the uniform solid fraction over the entire product. Therefore, squeeze casting process of rheological material developed in this study is suitable for forming the complex part.

Figure 12 shows photographs showing the fine microstructure of the product which were fabricated at $V_{L}=$ $0.1 \mathrm{~m} / \mathrm{sec}, V_{H}=1.0 \mathrm{~m} / \mathrm{sec}, f_{s}=0.2$. Dendrite phases for the product fabricated at solid fraction, $f_{S}=0.2$, were hardly shown. Because the branch of the dendrite might be crushed by EMS, the globularized phases were shown compared to the product fabricated at $f_{s}=0.0$. However, globularized microstructure of the product obtained from vertical squeeze casting process was quite different from that of the product directly obtained from EMS. It may be due to the fact that the melt flow in the die cavity did not smoothly occur because the product, that is, die cavity was the complicated thin plate in channel shape. During the EMS, control of the solid fraction is associated with reduction in temperature of the melt arising from convective heat transfer. The effect of EMS, which plays a role on crushing and refinement of dendrites, 


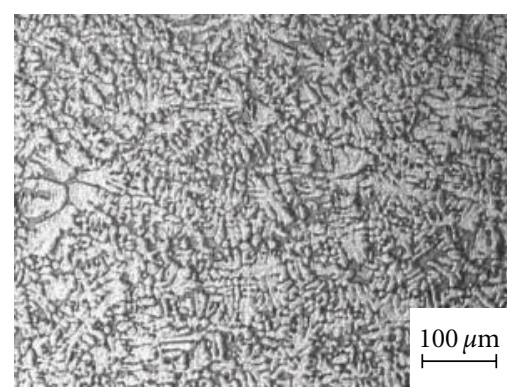

(a)

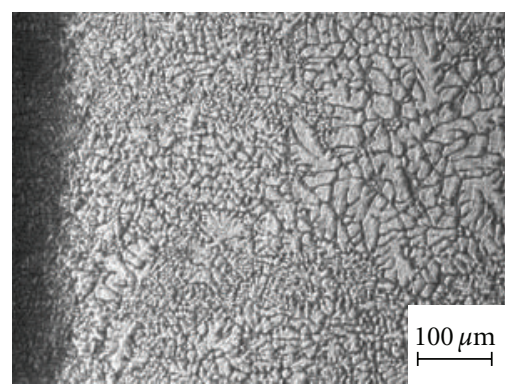

(d)

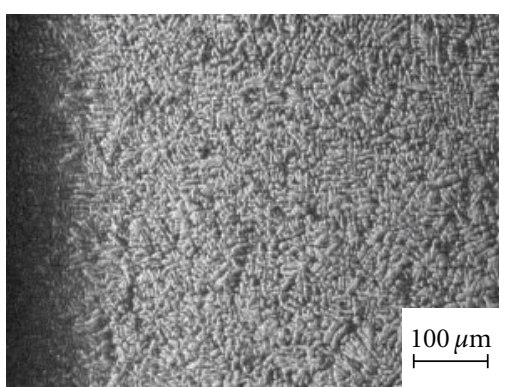

(b)

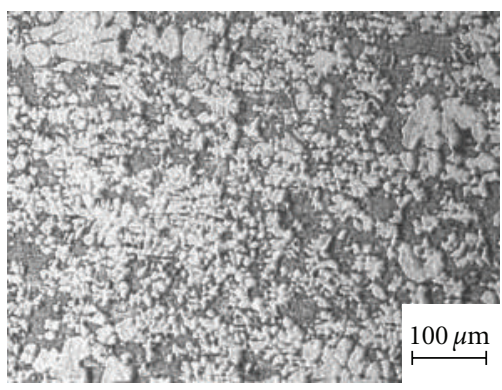

(e)

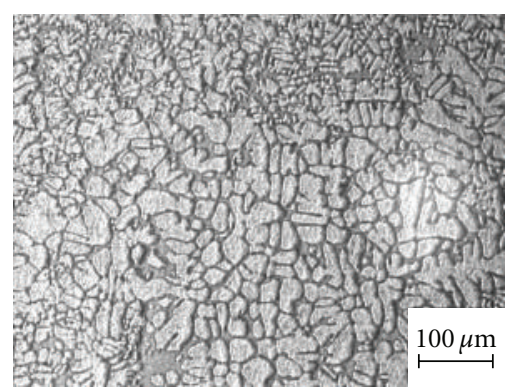

(c)

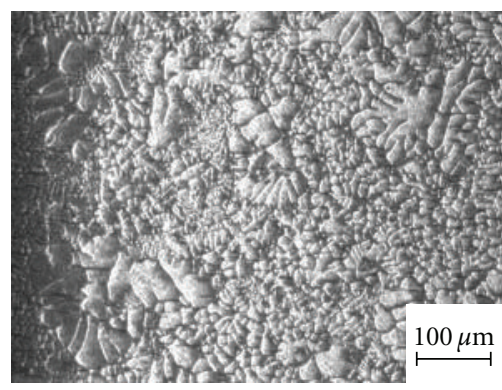

(f)

FIGURE 12: Microstructures of fabricated part by rheo-casting: $V_{L}=0.1 \mathrm{~m} / \mathrm{sec}, V_{H}=1.0 \mathrm{~m} / \mathrm{sec}$, Solid fraction: $20 \%$ ).
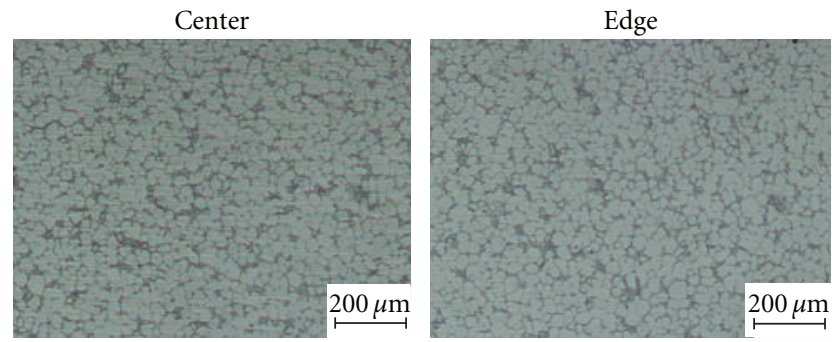

(a) 50 times magnification
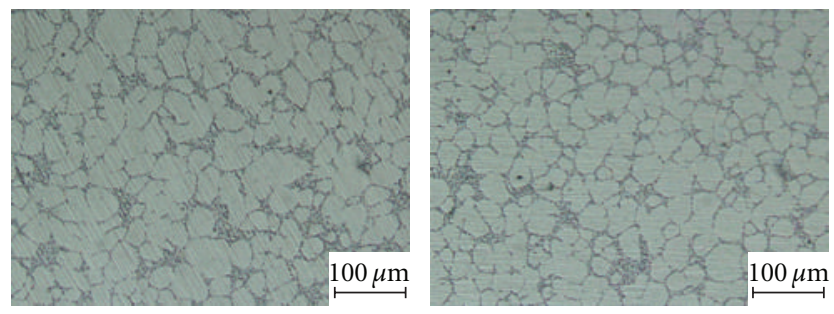

(b) 100 times magnification
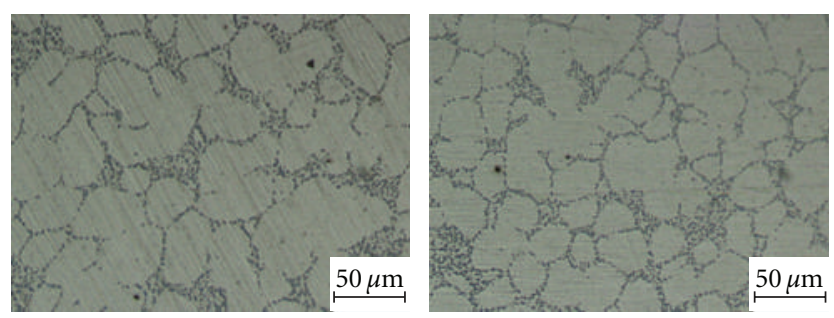

(c) 200 times magnification

FIGURE 13: Microstructure of rheology material (70\% solid fraction). was considerably weak because EMS was conducted for short time in order to get the melt with the low solid fraction.

\section{Fabrication of Module Bracket by EMS Rheo-Casting}

4.1. Fabrication of Slurry by EMS. In this experiment, A356 aluminum alloy was used for making slurry with the same EMS system (Section 2.1). Figure 13 shows a microstructure of rheological material. Uniformed and globular microstructure was well distributed.

4.2. Mold Design and Simulation with MAGMAsoft. To produce a module bracket using EMS, an optimal module bracket mold was designed by using a computer program to predict product defects by analyzing filling and solidification as shown Figures 14 and 15. The melt is filled from center to edge.

The possibility happening of shrinkage was high at spot regions. However, shrinkage will be removed due to direct pressure at center position by punch.

4.3. Inspection of Fabricated Module Bracket. Figure 16 is a fabricated sample by rheo-casting. Overall, there are no unfilling region and surface crack. To investigate the internal defect and particles distribution, observation of microstructure was conducted by optical microscope as shown in Figure 17. Overall, macroporosities were not founded. However, dendrite structures and liquid segregations were founded at regions 3 and 4 . Liquid segregation and dendrite structure cannot be controlled in liquid phase. The primary $\alpha$ and 


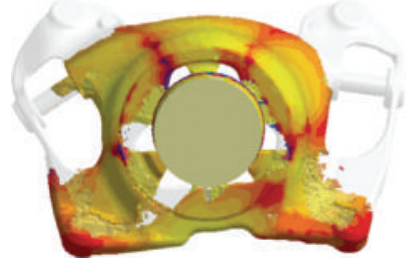

(a) $70 \%$ filled

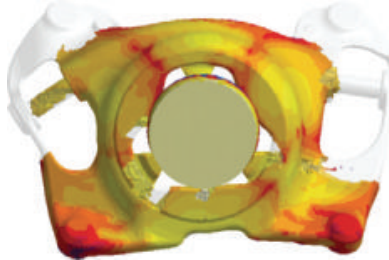

(b) $80 \%$ filled

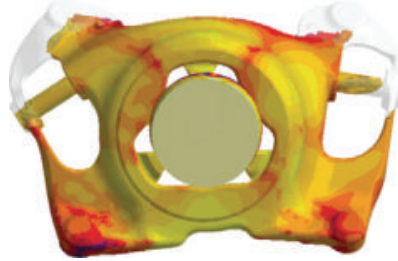

(c) $90 \%$ filled

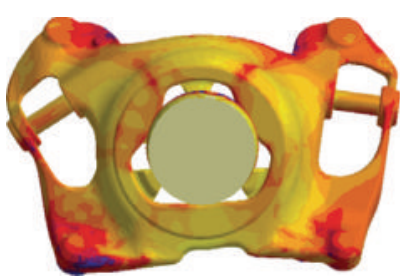

(d) $100 \%$ filled

FIGURE 14: Filling behavior of module bracket by rheology forging.

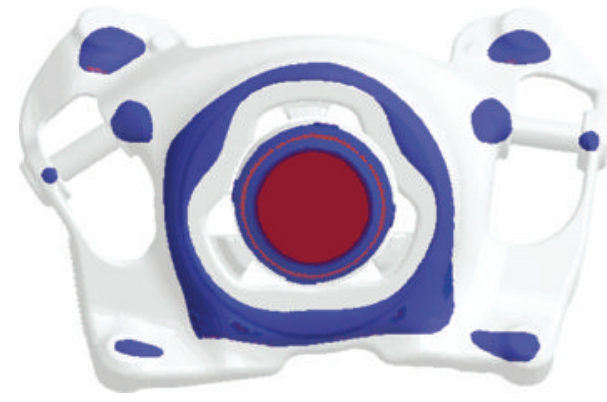

FIGURE 15: Solidification behavior of module bracket by rheology forging.

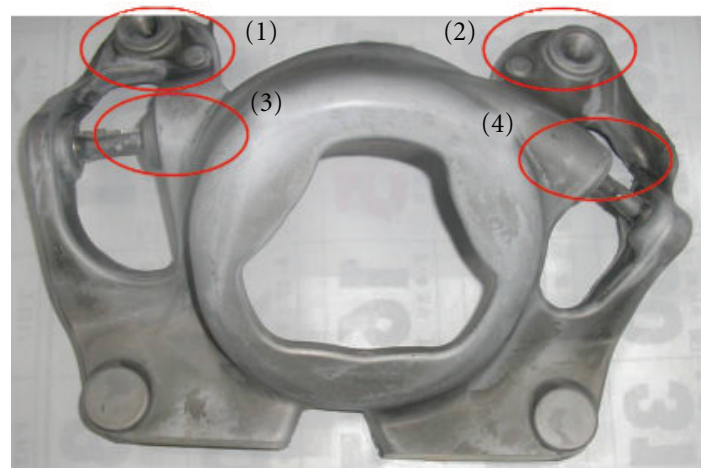

Figure 16: Fabricated module bracket and position of microstructure (initial slurry temperature: $600^{\circ} \mathrm{C}$, punch velocity: $50 \mathrm{~mm} / \mathrm{sec}$ and solid fraction: $70 \%)$.

eutectic phases were separated by the applied pressure at the mentioned positions. This liquid segregation was caused by nucleation of solid particles at the early solidification stage, which later grew to dendrite and rosette type structure by high liquid fraction. EMS is well affected between liquidus and solidus. Reduction of pouring slurry temperature could be done by the dendrite and liquid segregation. However, generally lower temperature requires more load in metal forming. In addition, unfilling and surface crack can easily take place. Therefore, the finding of optimal pouring temperature is very important.

\section{Fabrication of Knuckle Component by EMS Rheo-Casting}

5.1. Mold Design and Simulation with MAGMAsoft. To produce a knuckle using EMS, an optimal knuckle mold was

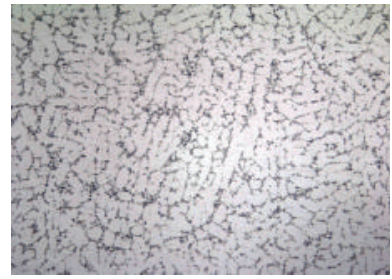

(a)

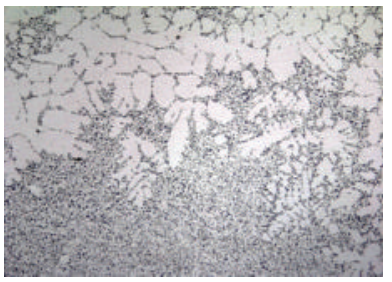

(c)

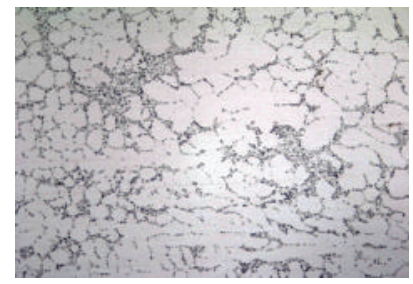

(b)

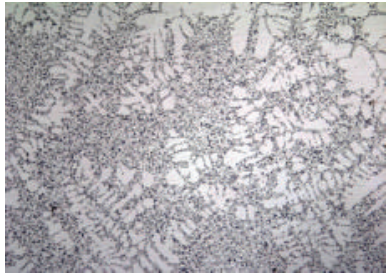

(d)
FIGURE 17: Microstructure of each position.

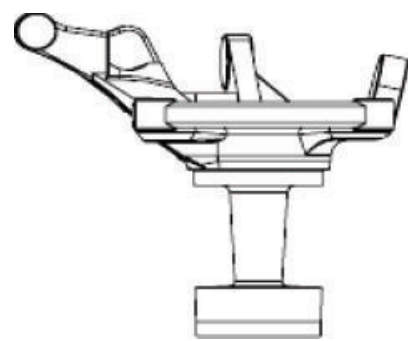

(a) Dimension of the gate $(\mathrm{mm})$

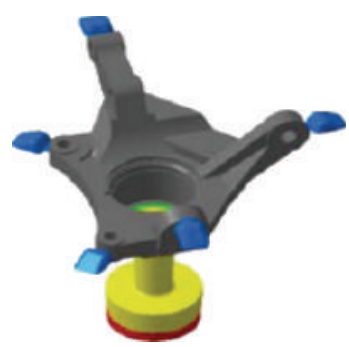

(b) Design of runner system
FIgURE 18: Geometry of gate and runner system for knuckle.

designed by using a computer program to predict product defects by analyzing filling and solidification. Figure 18 depicts the casting scheme of the knuckle describing the gate and the runner system. The sleeve and the gate were designed with a diameter of $80 \mathrm{~mm}$ and a height of $147.5 \mathrm{~mm}$, respectively. The overflow was designed to eliminate the oxide layer on the surface of the slurry and gaseous impurities occurring during production.

The analyses of filling and solidification were performed using condition 1 (a speed of $0.6 \mathrm{~m} / \mathrm{s}$ for the gate and of $0.2 \mathrm{~m} / \mathrm{s}$ for the cavity) and condition 2 (a speed of $0.1 \mathrm{~m} / \mathrm{s}$ for the gate and of $0.3 \mathrm{~m} / \mathrm{s}$ for the cavity). Figure 19 shows the behavior of filling in the knuckle by injection speed for each condition. Figure 19(a) shows how the materials 


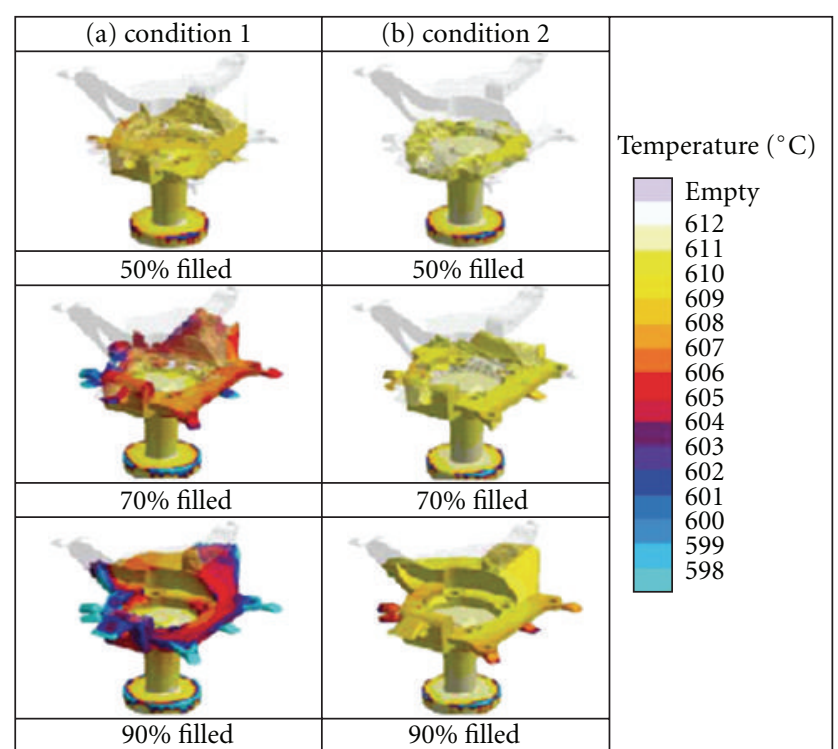

FIgUre 19: The comparison of filling behavior at conditions 1 and 2 .

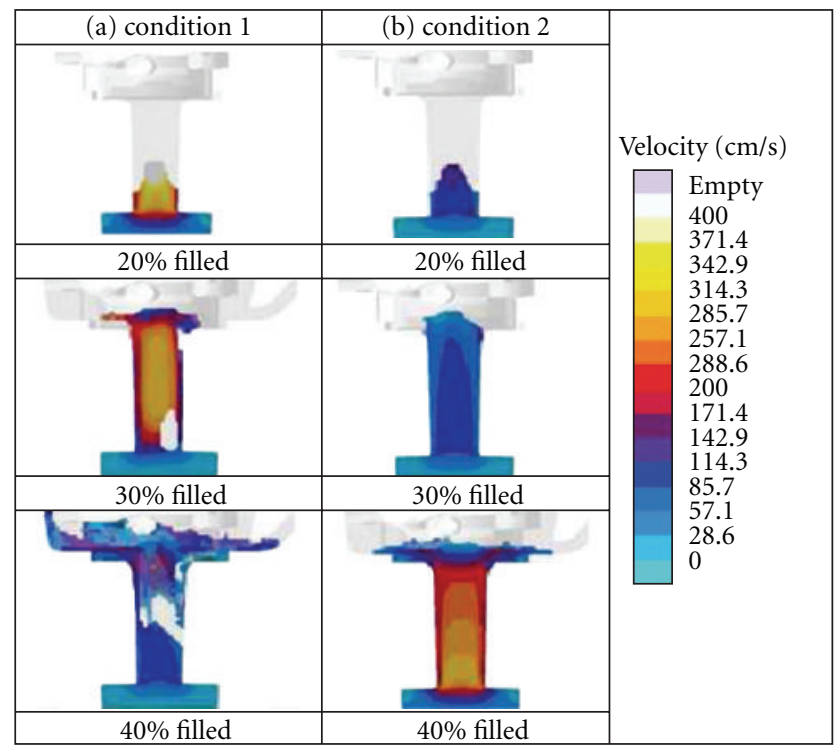

FIGURE 20: Comparison of velocity behavior at the runner.

spattered at the ingate when the cavity was filled to 50 and $60 \%$ using condition 1 . The temperature in the mold was altered by $20^{\circ} \mathrm{C}$ under condition 1 because of the increase in filling time. In contrast to condition 1 , the cavity was filled flawlessly around the gate and the product using condition 2 as shown in Figure 19(b). The deviation of temperature in the mold was found to be $7^{\circ} \mathrm{C}$ and the fraction of liquid phase was within $10 \%$. Figure 20 compares the behaviors of the flows at the gate for each condition. When the gate speed was $0.2 \mathrm{~m} / \mathrm{s}$, the mold was insufficiently filled after $30 \%$ of the filling was poured due to the high speed of the injection when filling the mold up to $30 \%$. It is evident that the turbulence of the flow spatters the material because after $40 \%$ of the filling was poured, the product was insufficiently filled. Thus, these results indicate that porosity occurs due to the presence of gas impurities in the knuckle. In Figure 20(b) it is clear that the gate was fully filled and a laminar flow was well developed.

5.2. Results of Knuckle Fabrication by Rheo-Casting. Figure 21 shows a photograph of the knuckle produced without EMS with solid fraction of $40 \%$. When the injection pressure was 450 bar and the injection speed was $0.2 \mathrm{~m} / \mathrm{s}$, the products were insufficiently formed due to solidification occurring in the sleeve while filling the cavity. Moreover, the surface quality was degraded because forming pressure did not transfer to surface of the product. Since low-speed casting resulted in an incomplete formation of the part and a poor surface quality, the injection speed was increased from $0.2 \mathrm{~m} / \mathrm{s}$ to $0.3 \mathrm{~m} / \mathrm{s}$. When the injection pressure was $450 \mathrm{bar}$ and the injection speed was $0.3 \mathrm{~m} / \mathrm{s}$, the resulting knuckle was sufficiently formed and its surface quality was excellent. When the injection speed was increased from $0.3 \mathrm{~m} / \mathrm{s}$ to $0.5 \mathrm{~m} / \mathrm{s}$ and the injection pressure was kept at $450 \mathrm{bar}$, large volume products were incompletely formed and had degraded surfaces.

To investigate the effect of EMS on the microstructures of products, the product was cast while varying electromagnetic current and time. Figure 22 shows photographs of the microstructure of the knuckle produced using EMS. The microstructure of the knuckle cast under each condition was investigated at the tip of the product, which can be difficult to form. When the stirring current was $60 \mathrm{~A}$ and stirring time was $5 \mathrm{~s}$, the dendritic structure was crushed somewhat but not completely. When the current was $60 \mathrm{~A}$ and the time was $10 \mathrm{~s}$, the structure was fine. The primary $\alpha$-Al phase particle size was $75 \mu \mathrm{m}$ and the roundness was 1.6. As the stirring time increased to $15 \mathrm{~s}$ with a $60 \mathrm{~A}$ stirring current, the crushed dendritic structure was recombined and coarsened. The primary $\alpha$-Al phase particle size was $79 \mu \mathrm{m}$ and the roundness was 1.7.

5.3. Mechanical Properties and Defect Analysis. Table 2 summarizes the mechanical properties of the knuckle formed with and without EMS by these conditions. To investigate the effect of EMS on the mechanical properties, the forming experiments were performed using stirring currents of $40 \mathrm{~A}$ and $60 \mathrm{~A}$ with stirring times of 5, 10 and $15 \mathrm{~s}$. The mechanical properties of the products using EMS were considerably enhanced compared with those of the products formed without EMS, but the values themselves were low. As air and oxides flowed into the products when the melts were stirred or were poured into the mold cavity, those impurities may have caused deterioration in the mechanical properties. The microstructures of the knuckles produced using EMS had very fine primary phase particles compared with those of the products formed without using EMS. Globular particles may have influenced the mechanical properties [7].

To investigate the cause of the deterioration of the mechanical properties of the knuckle produced by EMS, the interior of the product was X-rayed (Toshiba Tosray-150 HS), as shown in Figure 23. The final filling part, which 
TABLE 2: The mechanical properties of knuckle part with and without stirring according to each condition.

\begin{tabular}{|c|c|c|c|c|c|c|}
\hline$P(\mathrm{Mpa})$ & $V(\mathrm{~m} / \mathrm{s})$ & $C(\mathrm{~A})$ & $T_{s}(\mathrm{~s})$ & Heat treatment condition & Elongation $(\%)$ & UTS (MPa) \\
\hline 450 & 0.3 & 0 & 0 & $\mathrm{~T} 5\left(8 \mathrm{~h}\right.$ at $\left.170^{\circ} \mathrm{C}\right)$ & 1.9 & 145 \\
\hline 450 & 0.5 & 0 & 0 & $\mathrm{~T} 5\left(8 \mathrm{~h}\right.$ at $\left.170^{\circ} \mathrm{C}\right)$ & 2.1 & 132 \\
\hline 450 & 0.3 & 60 & 5 & $\mathrm{~T} 5\left(8 \mathrm{~h}\right.$ at $\left.170^{\circ} \mathrm{C}\right)$ & 2.2 & 204 \\
\hline 450 & 0.3 & 60 & 10 & $\mathrm{~T} 5\left(8 \mathrm{~h}\right.$ at $\left.170^{\circ} \mathrm{C}\right)$ & 2.4 & 212 \\
\hline 450 & 0.3 & 60 & 15 & $\mathrm{~T} 5\left(8 \mathrm{~h}\right.$ at $\left.170^{\circ} \mathrm{C}\right)$ & 1.5 & 164 \\
\hline 450 & 0.3 & 60 & 5 & T6 $\left(3 \mathrm{~h}\right.$ at $530^{\circ} \mathrm{C} 8 \mathrm{~h}$ at $\left.160^{\circ} \mathrm{C}\right)$ & 3.5 & 264 \\
\hline 450 & 0.3 & 60 & 10 & T6 $\left(3 \mathrm{~h}\right.$ at $530^{\circ} \mathrm{C} 8 \mathrm{~h}$ at $\left.160^{\circ} \mathrm{C}\right)$ & 3.6 & 250 \\
\hline 450 & 0.3 & 60 & 15 & $\mathrm{~T} 6\left(3 \mathrm{~h}\right.$ at $530^{\circ} \mathrm{C} 8 \mathrm{~h}$ at $\left.160^{\circ} \mathrm{C}\right)$ & 2.9 & 230 \\
\hline 450 & 0.3 & 60 & 15 & T6 $\left(3 \mathrm{~h}\right.$ at $530^{\circ} \mathrm{C} 8 \mathrm{~h}$ at $\left.160^{\circ} \mathrm{C}\right)$ & 6.7 & 286 \\
\hline
\end{tabular}

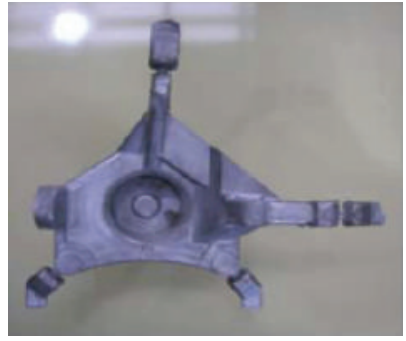

(a) $0.25 \mathrm{~m} / \mathrm{s} 450 \mathrm{bar}$

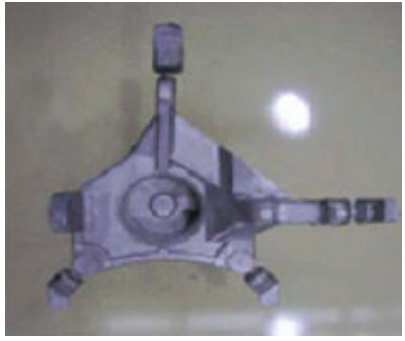

(b) $0.3 \mathrm{~m} / \mathrm{s} 450 \mathrm{bar}$

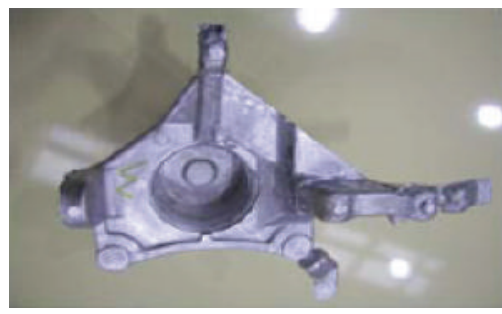

(c) $0.5 \mathrm{~m} / \mathrm{s} 450 \mathrm{bar}$

Figure 21: Photographs of the knuckle part fabricated by various casting conditions.

may have had defects, was the focus of the investigation. As can be seen from the photographs shown in Figure 23, numerous porosities were found inside the products that were cast after being stirred with 60 A of current for $15 \mathrm{~s}$. The air flowing into the products and the turbulent flow of the melts caused the porosities to develop. Moreover, air in the mold cavity could not be vented through air vents, thus the air remains in the mold cavity. Figure 24 shows a photograph of the microstructure of the knuckle including porosity and impurities. Observations of the microstructures revealed that porosities existed inside the products. These porosities may diminish mechanical properties and cause surface defects as the pores vent air to the surface of the products during heat treatments. To eliminate these porosities, the stirring current should be increased slowly preventing air from flowing into the products and air in the mold cavity could be completely vented through the five overflows while the melts filled the mold cavity.

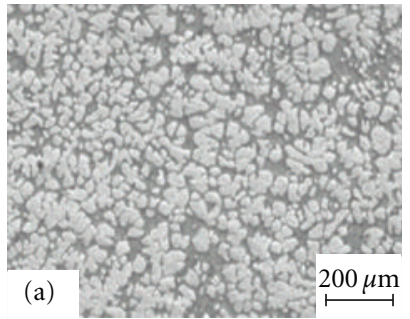

(a)

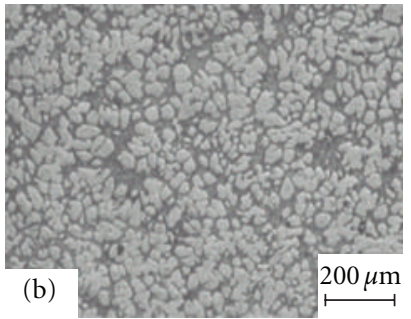

(b)

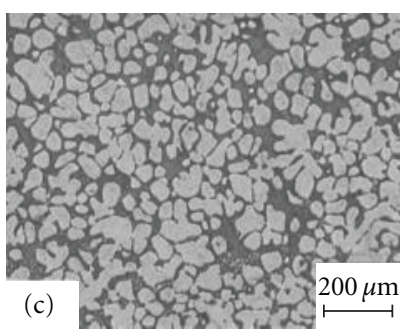

(c)

Figure 22: Microstructure of knuckle part at stirring current $60 \mathrm{~A}$ for (a) $5 \mathrm{~s}$; (b) $10 \mathrm{~s}$; (c) $15 \mathrm{~s}$.
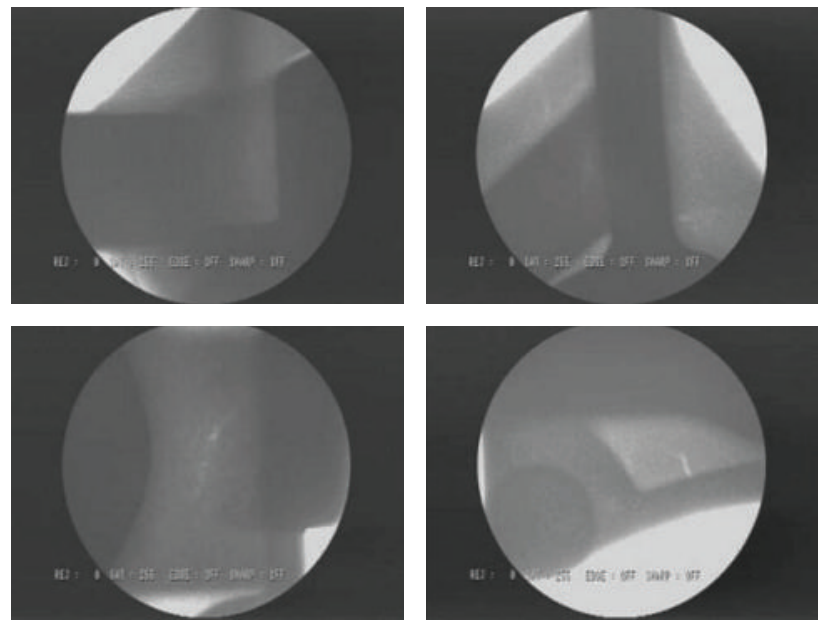

FIgURE 23: The X-ray photograph to observe inside knuckle. 


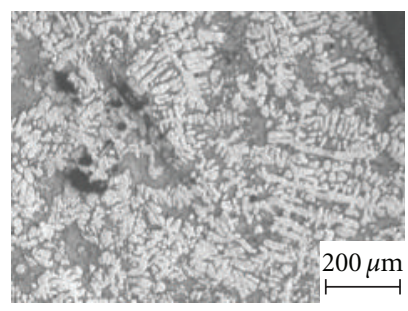

(a)

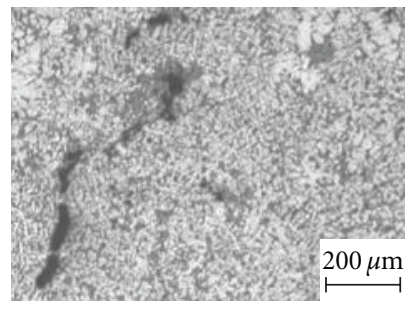

(c)

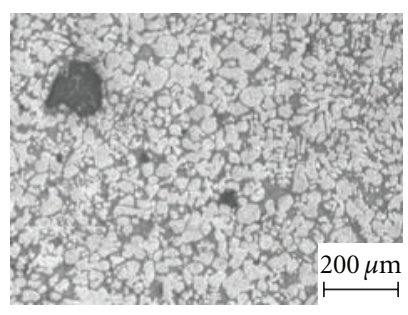

(b)

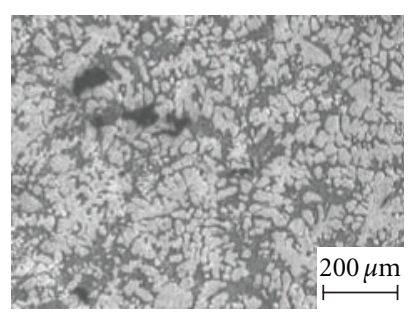

(d)
FIGURE 24: The microstructure of knuckle including defects such as porosity and segregation of liquid phase $\left(C: 60 \mathrm{~A} ; T_{s}: 20 \mathrm{~s}\right)$

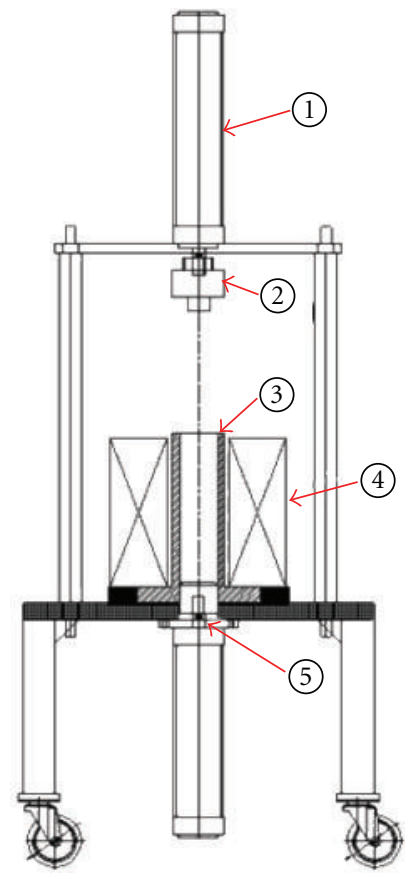

Figure 25: Schematic diagram of the vacuum casting system ((1) air cylinder, (2) Injection punch, (3) Sleeve, (4) Case, (5) Moving bottom punch).

\section{Fabrication of Knuckle Component by EMS Two Type Rheo-Forging with Vacuum Pump}

6.1. EMS under Vacuum for Rheological Billet Fabrication. To remove oxidization products and hydrogen gas from the molten metal, nitrogen gas was injected into the melt for $15 \mathrm{~min}$. Oxidization products and impurities were thus cleared away from molten metal surface [8].

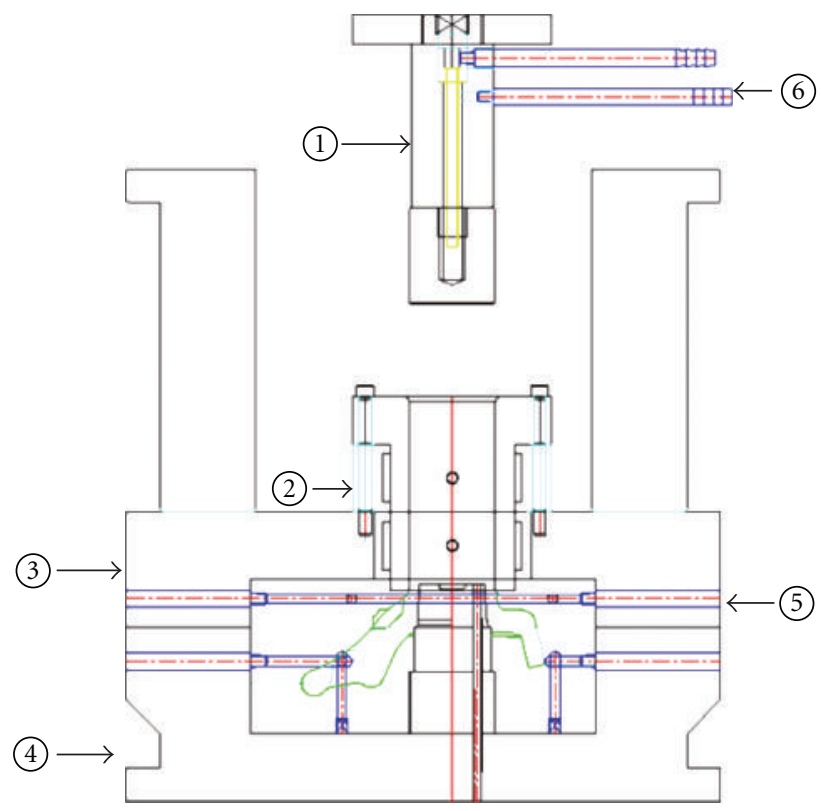
(1) Punch
(4) Lower die
(2) Sleeve
(5) Heating hole
(3) Upper die
(6) Cooling pipe

Figure 26: Schematic of indirect-type die set for rheo-forging and product.
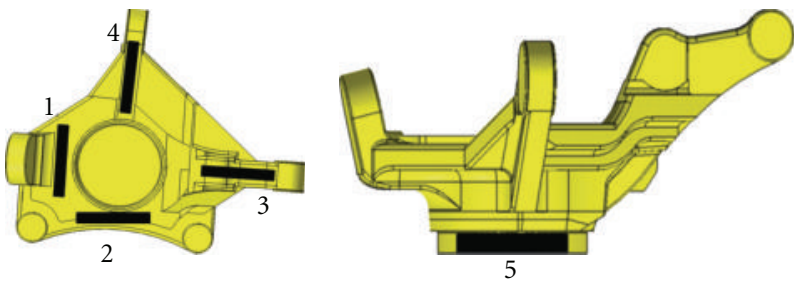

Figure 27: Positions of sample to observe in microstructure.

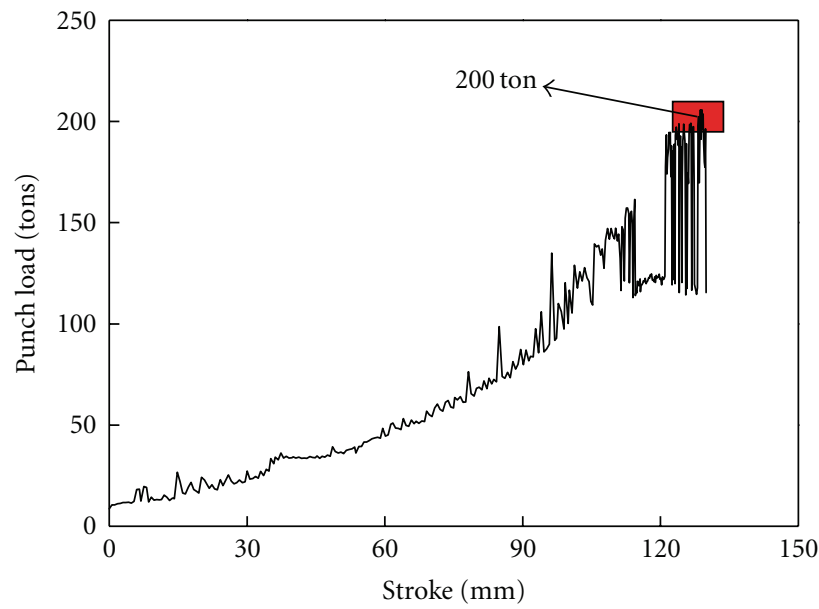

Figure 28: Stress of punch according to stroke for A356 at $588^{\circ} \mathrm{C}$ $\left(S_{f}=40 \%\right)$ in DEFORM-3D. 


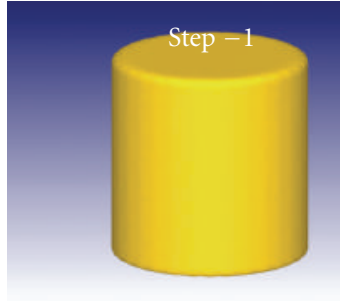

(a) $0 \mathrm{~mm}$

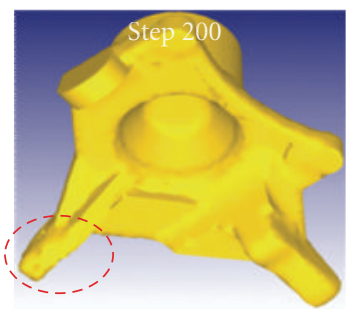

(c) $110 \mathrm{~mm}$

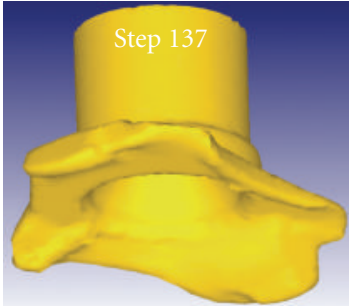

(b) $80 \mathrm{~mm}$

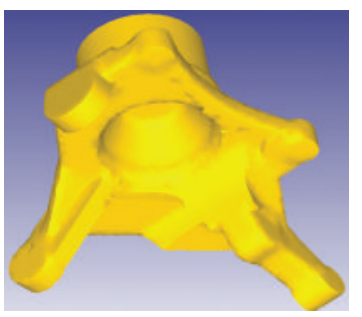

(d) $130 \mathrm{~mm}$
FIGURE 29: Shape change results according to punch stroke in DEFORM 3D.
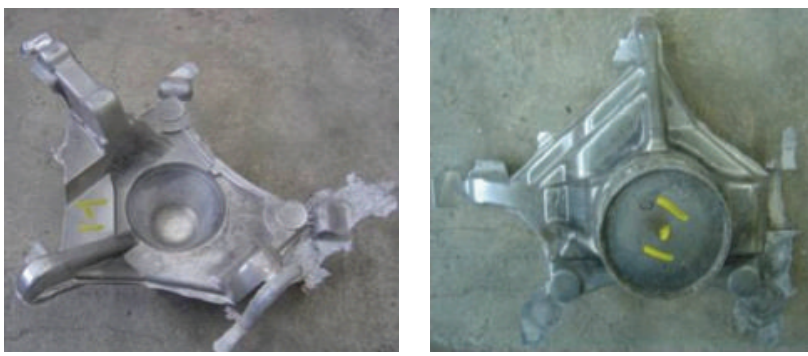

(a) Pouring $S_{f}=30 \%\left(600^{\circ} \mathrm{C}\right)$
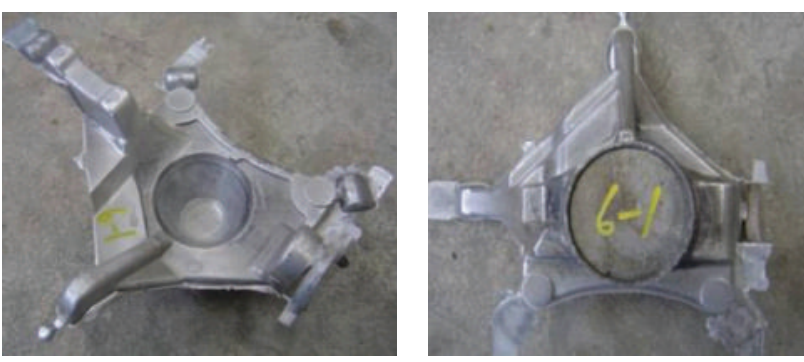

(b) Pouring $S_{f}=40 \%\left(588^{\circ} \mathrm{C}\right)$

Figure 30: Result of indirect rheo-forging test of rheological materials.

In aluminum alloys, hydrogen gas readily makes holes within the alloy during solidification. In addition, hydrogen gas has the highest solvency within aluminum alloy compared to other constituents of air, such as oxygen and nitrogen. Consequently, gas hole formation and porosity are increased within the alloy as the temperature decreases, degrading its mechanical properties.

Figure 25 shows schematic diagram of the EMS and vacuum pump. The EMS system operated with a threephase current at $60 \mathrm{~A}$. After the molten metal was poured, the injection punch was moved to the surface of the top

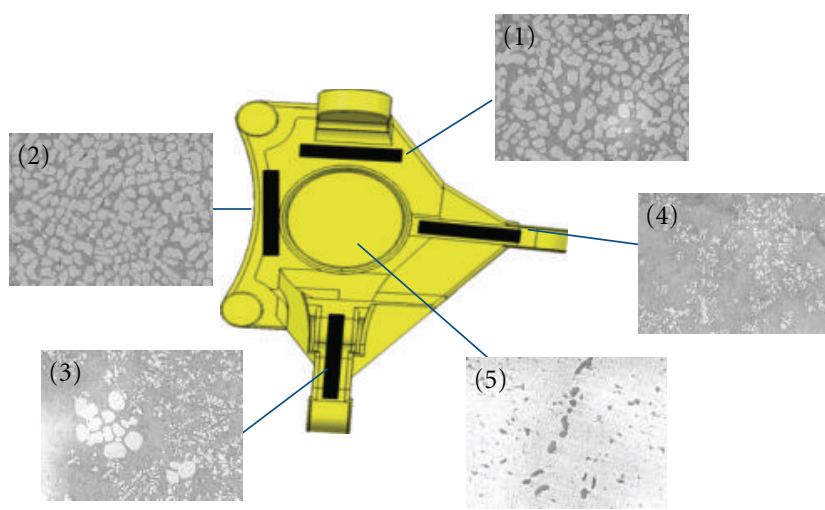

Figure 31: Microstructures of knuckle at each position $\left(S_{f}=40 \%\right.$, $\left.588^{\circ} \mathrm{C}\right)$.

sleeve and the EMS was operated under vacuum. This system prevents oxidation of the molten metal and air indraft.

6.2. Die Design and Simulation with DEFORM 3D. Knuckles were fabricated by a press machine. To decrease the process cycle time, the direct forging type is required, and Figure 26 shows the schematic of the indirect-type experimental procedure in the rheo-forging knuckle sample.

The temperature was controlled for achieving the solid fraction between $30 \%$ and 50\%. Solid fraction (pouring temperature) is variable in rheo-forging. Figure 27 shows the positions on the test piece that were subjected to tensile testing. The regions of each position were also studied by microscope. In order to observe the differences of the mechanical properties at different locations on the test piece, microstructure observation was carried out.

Before the experiment was started for the required forging load was calculated by simulation, considering the capacity of the press machine, with a maximum 200 Tons. As shown in Figure 28, the required load was about 200 Tons at $588^{\circ} \mathrm{C}(40 \%$ solid fraction). Figure 29 shows the shape change with respect to the punch stroke. At the near end of punch displacement of about $110 \mathrm{~mm}$, most of cavities were filled, except for marked region as shown Figure 29(c). When the punch displacement reached about $130 \mathrm{~mm}$, all cavities were fully filled.

6.3. Results of Knuckle Fabrication by Rheo-Forging. Figure 30 shows the real samples fabricated with respect to various pouring temperatures. All samples were completely filled above the pouring temperature of $588^{\circ} \mathrm{C}$. Real samples showed similar filling behavior as the simulation results in indirect forging.

In semisolid forming, liquid segregation easily occurred at high velocity due to the thixotropic characteristic. High shear rate resulted in decreased viscosity for a given solid fraction. Material having low solid fraction flowed easily compared with already hardened material. As a result, segregation occurred in a wide region. On the contrary, almost primary $\alpha$ phase is shown Figure 31 at position 5 . Position 5 region was directly contacted with the punch. 
Material flow was slower than that of the other regions. The contacted region was rapidly cooled. As previously stated, a material hardened by the decreasing temperature flows less easily than materials in liquid state. The remaining liquid material is squeezed. It moves down to the other cavities. For this reason, liquid phase is rare at position 5 .

\section{Summary}

The applied EMS fabrications of automobile components were studied by simulation and experiment. The following conclusions were obtained.

(1) It was found from the microstructural observation that the fine and spheroidized primary $\alpha$-Al phase particles were obtained, as a result of products by EMS.

(2) The analysis of filling products using MAGMAsoft (casting analysis software) or DEFORM 3D (forging analysis software) was conducted, and based on the analysis results, the optimized mold design scheme was constructed, predicting the defects that may take place during forming.

(3) Porosity is removed by the forging pressure. However, the molten aluminum alloy easily takes up hydrogen gas during solidification under exposure to the atmospheric environment. Defects such as porosity and oxide in the material could be removed by application of a vacuum during EMS.

(4) In the rheo-forging process, segregations was remarkably occurred at branches of the knuckle. It must be controlled to obtain uniform mechanical properties according to the changing process condition.

(5) In rheo-forming process, the EMS could be easily applied during fabrication, and it is very effective method to increase the mechanical properties.

\section{Acknowledgments}

This work was financially supported by the Ministry of Knowledge Economy (MKE) and Korea Institute for Advancement in Technology (KIAT) through the Workforce Development Program in Strategy Technology by the National Research Foundation of Korea (NRF) grant funded by the Korea government (MEST) (no. 2009-0081077), and by the National Core Research Center (NCRC). The authors would like to express their deep gratitude to the Ministry of Science \& Technology (MOST) for its financial support.

\section{References}

[1] M. C. Flemings, "Behavior of metal alloys in the semisolid state," Metallurgical Transactions A, vol. 22, no. 5, pp. 957-981, 1991.

[2] C. G. Kang, P. K. Seo, and Y. P. Jeon, "Thixo diecasting process for fabrication of thin-type component with wrought aluminum alloys and its formability limitation," Journal of Materials Processing Technology, vol. 160, no. 1, pp. 59-69, 2005.

[3] A. Pola, R. Roberti, E. Bertoli, and D. Furloni, "Design and production of new aluminum thixotropic alloys for the manufacture of structural components by semisolid die casting," Diffusion and Defect Data Part B, vol. 116-117, pp. 58-63, 2006.

[4] D. Liu, H. V. Atkinson, P. Kapranos, W. Jirattiticharoean, and H. Jones, "Microstructural evolution and tensile mechanical properties of thixoformed high performance aluminium alloys," Materials Science and Engineering A, vol. 361, no. 1-2, pp. 213224, 2003.

[5] K. Sukumaran, B. C. Pai, and M. Chakraborty, "The effect of isothermal mechanical stirring on an Al-Si alloy in the semisolid condition," Materials Science and Engineering A, vol. 369, no. 1-2, pp. 275-283, 2004.

[6] C. G. Kang, P. K. Seo, and Y. I. Son, "The effect of velocity control method on the part characteristic in semi-solid die casting," The Korean Society of Mechanical Engineers A, vol. 10, pp. 2034-2043, 2002.

[7] C. P. Hong and J. M. Kim, "Development of an advanced rheocasting process and its applications," Diffusion and Defect Data Part B, vol. 116-117, pp. 44-53, 2006.

[8] S. Lee and B. J. Ye, "The variation of pore distribution behavior according to melt treatments for $\mathrm{Al}$ alloys," The Korean Foundrymen's Society, vol. 21, no. 6, pp. 343-349, 1999. 

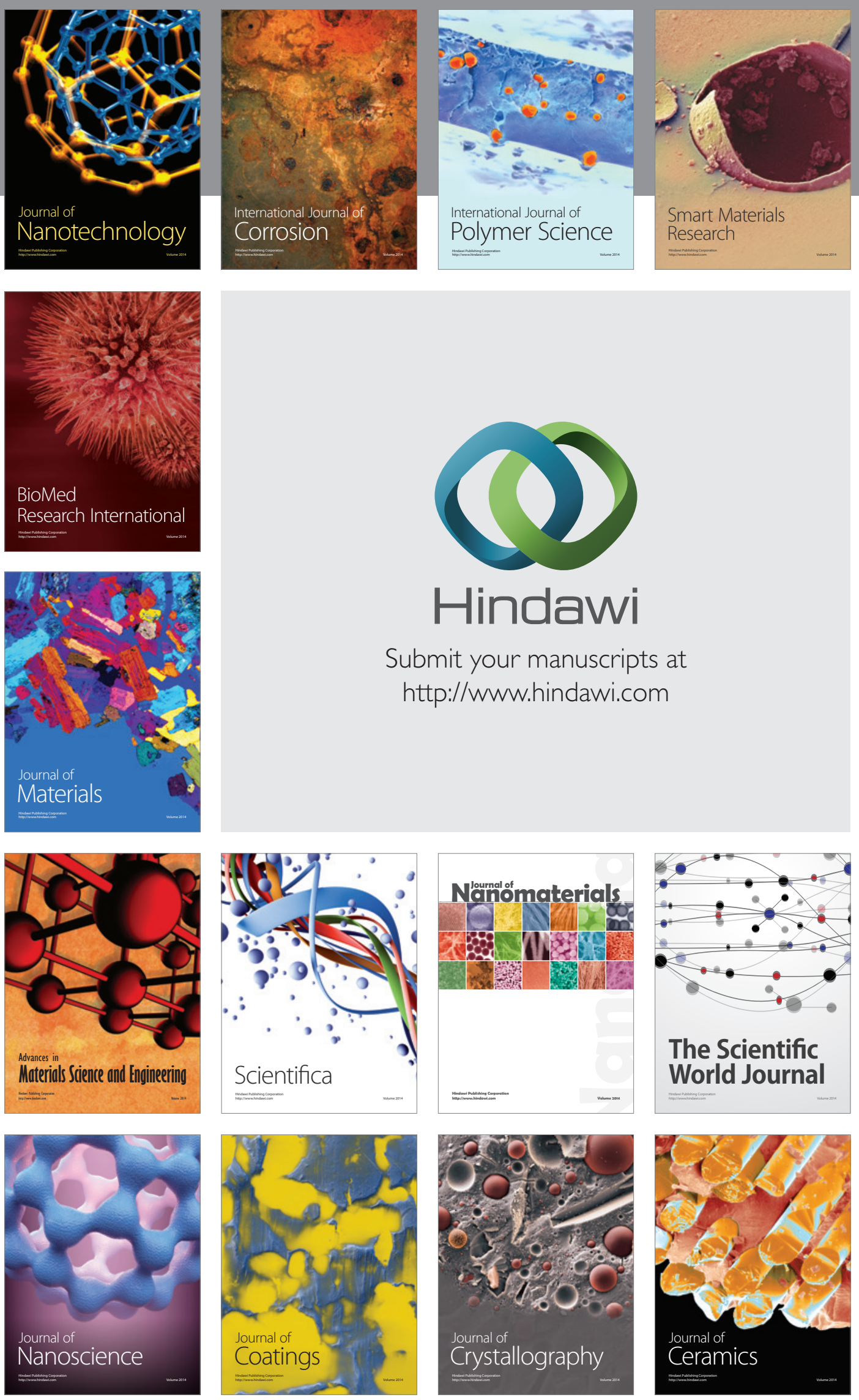

The Scientific World Journal

Submit your manuscripts at

http://www.hindawi.com

\section{World Journal}

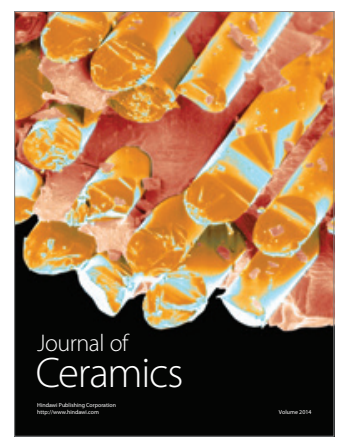

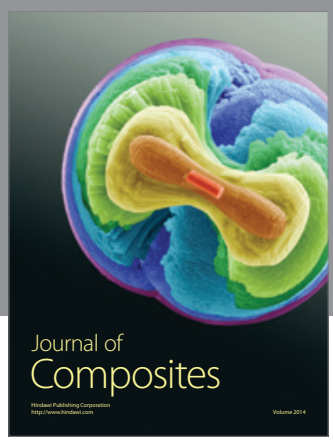
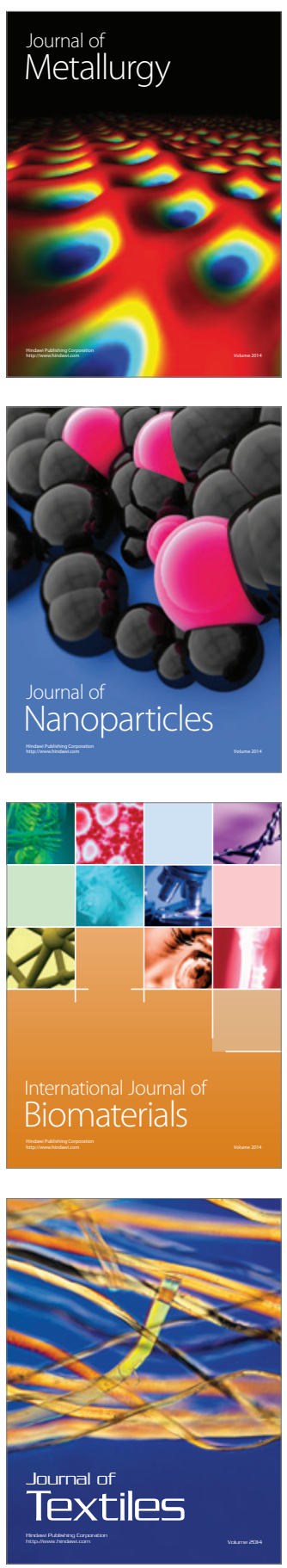